\title{
CONSIDERAÇÕES METODOLÓGICAS PARA A ESTRUTURAÇÃO DE UMA ABORDAGEM PROJETUAL COERENTE COM O DESIGN SUSTENTÁVEL
}

\section{METHODOLOGICAL CONSIDERATIONS TO THE STRUCTURING OF A PROJECTUAL APPROACH CONSISTENT WITH THE SUSTAINABLE DESIGN}

\author{
André de Souza Lucca ${ }^{1}$ \\ Universidade Federal do Maranhão - UFMA - São Luís - Maranhão - Brasil \\ aslucca@yahoo.com.br
}

\begin{abstract}
Resumo
Baseado em uma revisão bibliográfica, o presente texto procura discutir as relações entre o método projetual e o desenvolvimento de produtos e serviços buscando fornecer subsídios para a estruturação de uma abordagem metodológica coerente com a ótica do design sustentável. Um dos pressupostos é que, no design sustentável, as variáveis sociais e ambientais particulares de um território tornam-se o sistema de referência e adquirem a força para endereçar a interpretação dos subproblemas e das subsequentes decisões de projeto. Entre as conexões encontradas, torna-se claro a necessidade da adoção de uma abordagem flexível, capaz de ser modificada, implementada ou periodicamente atualizada em função do tema e do contexto de cada projeto. Este tipo de abordagem deve ser capaz de orientar o projetista na busca por soluções sustentáveis, portanto, as fases analíticas de compreensão dos problemas deverão ser estendidas em relação às tradicionais etapas de projeto. Outros sim, percebeu-se que o objeto do projeto transformou-se num sistema que ao mesmo tempo se desdobrou e se complexificou. Um sistema que compreende também o contexto no qual o produto do projeto vai se colocar. Esta intensa conexão dos problemas com o território requer o uso de ferramentas de investigação adequadas para uma exploração contextual. Neste caminho, o metaprojeto apresenta-se como um momento necessário para a correta percepção e a análise dos problemas identificados. Mais do que encontrar respostas definitivas, o objetivo deste ensaio é fornecer uma contribuição efetiva para a área de pesquisa e desenvolvimento de produtos e serviços, auxiliando na concepção de projetos orientados para a sustentabilidade.
\end{abstract}

Palavras-chave: método; design de produtos e serviços; inovação sustentável.

\section{Introdução}

As metodologias de projeto concentram a sua atenção sobre os modos nos quais uma ação, o projeto, leva a um resultado: um produto, um serviço ou um sistema. O dilema de como resolver um determinado problema acontece, inicialmente, no momento da escolha do método, ou seja, na 
seleção de qual processo utilizar para concretizar uma solução. A escolha do processo, por sua vez, se faz concentrando-se sobre o grupo de ações necessárias para o alcance de um objetivo de projeto. De acordo com Bonsiepe (1978, p. 23-24, tradução nossa), "esses grupos formam o conjunto de ações consecutivas que encaminham o projeto para a sua concretização". Da metodologia se espera um auxílio para determinar a sucessão das ações (quando fazer algo), o seu conteúdo (o que fazer) e a definição dos procedimentos específicos a serem implementados (como fazer, quais técnicas e ferramentas usar). Assim, a metodologia deve oferecer uma série de diretrizes e esclarecer a estrutura do processo projetual.

Não obstante, uma metodologia não deve ser confundida com um receituário, porque receita significa rotina, isto é, um modo preestabelecido para se alcançar um determinado fim. Para Bonsiepe (1975, p. 146, tradução nossa), "uma metodologia não tem um fim próprio, a sua justificativa é dada mais pelo seu caráter instrumental”. Os problemas não são padronizáveis e muito raramente uma mesma solução pode ser implementada diante de problemas provenientes de diferentes contextos, até mesmo, se tais problemas possuem origens análogas. Ao contrário, as soluções, como os métodos, podem ser adequadas ou adaptadas e este atributo nos lembra uma outra característica importante que deve ter uma metodologia projetual, a flexibilidade.

Cada projeto levanta problemas que devem ser resolvidos. Depois de ter estudado a situação a partir de cada ponto de vista, ocorre escolher a metodologia que forneça o melhor caminho para se alcançar as repostas. De acordo com Watanabe (2004, p. 4, tradução nossa) "é como reconstruir um quebra-cabeças muito intricando e complicado, mas a diferença entre resolver um problema de projeto e resolver um quebra-cabeças, consiste no fato que não é suficiente satisfazer as condições iniciais”. Uma outra propriedade indicada por Watanabe (2004, p. 6, tradução nossa) é que um bom método deve corresponder ao que se espera: "Não se sabe exatamente a quem ele deve agradar, mas em primeiro lugar deve satisfazer o projetista, em seguida, também aqueles que o usam". Um bom método, e o consequente conjunto de ações que o definem, deve ser coerente, compreensível e, antes de tudo, replicável. Portanto, um método deve ser simples, dimensionado pela extensão dos problemas que deseja resolver e aplicável por outros projetistas. Ainda segundo Watanabe (2004. p. 6-7, tradução nossa): “A projetação começa com o exame da situação. Se realizam estudos, se desenvolvem ideias e gradualmente os detalhes começam a encontrar os seus lugares. É um processo de escolha de uma linha de ação".

Para Bonsiepe (1978, p. 24, tradução nossa), “o método é uma característica particular de um grupo de ações". As ações estruturadas na forma de método agem como guia e orientam o projetista em seu trabalho. Ademais, o método se exprime através da escolha deliberada e da organização das subações. Estas deveriam, em todo o caso, ter características de programa e serem aplicáveis em mais de uma ocasião, ou seja, assegurando a sua replicabilidade. Segundo Bonsiepe 
(1975, p. 146-147, tradução nossa) "é por esta prerrogativa que a metodologia é definida como um conjunto de ferramentas de navegação".

Claramente, quando se faz uma interpretação muito objetiva do método é possível concluir que na sua práxis cada passo se torna uma ação premeditada e, por isso, os métodos devem ser altamente estruturados e imutáveis. Segundo Bonsiepe (1978), tais características entram em direto conflito com as particularidades do design:

\footnotetext{
Como no projeto deve ser considerado uma série de atributos (produtivos, ambientais, socioeconômicos, culturais, entre outros), os métodos de design devem ser elaborados de forma mais livre, admitindo os componentes casuais e não estruturados e, portanto, possuindo um alto nível de flexibilidade e aplicabilidade (BONSIEPE, 1978, p. 28, tradução nossa).
}

Deste modo, o primeiro passo que se deve fazer para afrontar a complexidade dos problemas de projeto é procurar uma forma para particionar as entidades complexas em entidades simples. Em outras palavras, a sugestão metodológica oferecida por Bonsiepe (1978, p. 28, tradução nossa) é aquela de "atacar o problema pela sua parte mais acessível, dividindo o problema em vários subproblemas”. Subdividir um problema complexo de design significa hierarquizá-lo. Os diversos grupos de variáveis são ordenados em base a sua relativa importância. O processo de divisão de um problema, para Bonsiepe (1978, p. 28, tradução nossa), pode ser representado visivelmente na forma de um gráfico ou, mais precisamente, "através de um diagrama em forma de árvore constituído por elementos (as variáveis) e pelas linhas que os ligam (as específicas relações entre as variáveis)".

Um problema de projeto é constituído por dois elementos: a forma e o seu correspondente contexto. O contexto, identificável com a soma dos requisitos e restrições, cruza o seu complemento enquanto que a forma é a soma das características que satisfazem o contexto. Bonsiepe (1978, p. 29, tradução nossa) sugere a "elaboração de uma lista com as possíveis contradições entre a forma e o contexto". Para Bonsiepe (1978, p. 29-30, tradução nossa): "Sendo extremamente difícil, senão impossível, descrever uma forma que corresponde ao seu contexto é preferível listar as suas possíveis contradições". Deste modo, o processo projetual pode ser interpretado como um esquema concebido para neutralizar ou eliminar aqueles fatores que causam as contradições indesejáveis entre a forma e o contexto. De fato, somente quando se reconhece uma contradição (um estado de deficiência por exemplo) é que se expressa um problema de design. Portanto, na primeira fase do seu trabalho, o designer deveria se concentrar sobre aqueles fatores que podem influenciar o equilíbrio desejado entre o produto e o seu contexto.

\section{Abordagem metodológica para projetos sustentáveis}


Projetar é uma atividade que associa conhecimentos de diferentes áreas. Se entendemos as Ciências Aplicadas como as disciplinas que transformam os resultados da pesquisa científica em tecnologia, o Design representa uma disciplina, entre outras, que a torna utilizável em produtos, serviços e sistemas. Para fazer isso, emprega conteúdos provenientes de áreas muito diversas como: engenharia, economia, administração, sociologia, ecologia, antropologia, psicologia, comunicação, artes, entre outras.

Qualquer processo de projeto é por sua própria natureza complexo. O agir projetual pode ser definido como a tarefa de dar forma aos produtos industriais. Para fazer isso o projetista, integrando e concentrando as diferentes configurações dos produtos, oferece respostas para uma série de perguntas relativas ao seu aspecto, a sua performance, a sua construção e a sua relação com os outros produtos e artefatos. Segundo Badalucco e Chiapponi (2009, p. 24-25, tradução nossa), "para conseguir responder a estas perguntas, os projetistas têm progressivamente desenvolvido ferramentas e métodos que têm permitido a eles dar a justa importância aos fatores que determinam a forma de um produto".

Durante a sua evolução, o Design tem construído um catálogo de ferramentas e de técnicas que tem permitido aos projetistas transitar autonomamente sobre estes variados campos. Uma consequência direta desta capacidade é a propriedade que o Design possui de se declinar em razão dos objetivos que deseja alcançar. Para Badalucco e Chiapponi (2009):

Uma vez que o design é entendido como uma atividade endereçada para preencher as carências e as necessidades do homem, este design deverá necessariamente considerar as variáveis econômicas, ecológicas e socioculturais que compreendem tais necessidades. Assim, tornam-se supérfluos muitos adjetivos que qualificam algumas formas de projeto como o ecodesign, o design verde, o design social (BADALUCCO e CHIAPPONI, 2009, p. 24-25, tradução nossa).

Ainda segundo os autores:

\begin{abstract}
A ideia que exista um ecodesign pode levar a pensar que possa existir um design "não eco", ou seja, no qual é possível não considerar, ou colocar nos últimos degraus da escala das prioridades, a configuração ambiental dos produtos. Na realidade, os aspectos ambientais têm hoje o mesmo peso daqueles funcionais, de performance, de comunicação ou produtivos [...] portanto, deveriam fazer automaticamente parte do centro da atenção do projetista (BADALUCCO e CHIAPPONI, 2009, p. 61-62, tradução nossa).
\end{abstract}

Aquilo que distingue um projeto de Design que favorece, contemporaneamente, a sustentabilidade e a competitividade das atividades produtivas, de um projeto de Design habitual é a precisão na fase analítica com a qual é examinada, do ponto de vista socioeconômico, técnicoprodutivo e ambiental, a relevância do sistema-produto e das soluções propostas em relação a um determinado contexto sociopolítico e geográfico, isto é, quando o objetivo do projeto é alcançar resultados mais amplos, além do projeto de um produto ou de uma família de produtos para um 
específico setor industrial, como na orientação de um inteiro setor produtivo presente num determinado território. Naturalmente, tal projeto pode existir somente dentro de um panorama mais amplo, como aquele integrado em uma estratégia de valorização territorial e, portanto, compreendido como uma atividade multidisciplinar que envolve muitos atores, como observam Badalucco e Chiapponi (2009):

\begin{abstract}
A necessidade de envolver competências diversas, de considerar as intervenções nas suas diferentes escalas e de estar coerente com o contexto territorial de referência, requer uma atitude multidisciplinar ao projeto. Por este motivo, a abordagem metodológica deverá prever a implicação de especialistas em vários setores e nas várias fases do projeto (BADALUCCO e CHIAPPONI, 2009, p. 60, tradução nossa).
\end{abstract}

Portanto, do ponto de vista metodológico, no design orientado para a sustentabilidade, as variáveis sociais e ambientais particulares de um território tornam-se requisitos referenciais, ou seja, prioritários e com o poder de endereçar a interpretação dos subproblemas e das decisões subsequentes de projeto. Na prática, a carga de informações que o designer deverá lidar será maior, como também, as relações de tais variáveis com o sistema de produção e com o inteiro ciclo de vida do produto, do serviço ou do sistema que o projeto irá propor.

Uma estrutura metodológica capaz de fazer frente a tal complexidade deverá ser, sobretudo, adaptável. Badalucco e Chiapponi (2009, p. 68, tradução nossa) convidam, além disso, a "basear-se numa abordagem metodológica flexível, capaz de ser modificada, implementada ou periodicamente atualizada em função do tema e do contexto do projeto". Os benefícios socioambientais resultantes de uma tal abordagem devem ser claramente identificáveis entre os objetivos de projeto. Para fazer isso, tais objetivos podem ser elaborados através de uma investigação contextual ou através de processos participativos e de co-design onde a população e os atores socioeconômicos tenham voz. Para Badalucco e Chiapponi (2009, p. 68, tradução nossa), "um projeto sustentável será de fato um bom projeto somente se for capaz de fornecer, ao mesmo tempo, também um benefício econômico evidente". Reconhecendo a importância deste raciocínio, é possível também acrescentar que os benefícios sociais e ambientais devem seguir esta meta.

No campo da prática profissional, esta abordagem faz emergir uma área de atuação ainda pouco considerada no âmbito do Design, ou seja, aquela do planejamento das atividades produtivas em nível local. É conhecida a participação de engenheiros, arquitetos e urbanistas nas administrações públicas, principalmente municipais. As suas competências, predominantemente projetuais, são indispensáveis para a planificação e o desenvolvimento urbano das cidades. Analogamente, os designers podem levar as suas competências para dentro das secretarias de indústria e comércio e participarem da planificação das atividades produtivas em âmbito local. Logicamente, o nível de atuação do designer será aquele de analisar e propor possíveis interações 
entre os diversos setores da economia local objetivando a sua valorização, como nas indústrias, no comércio, nos serviços, no turismo, no artesanato, na agricultura e assim por diante. A relevância de uma tal participação pode se verificar através da programação de ações coordenadas, como na construção da identidade territorial, na proposta de novos arranjos produtivos, na valorização dos produtos e dos serviços que destes derivam, bem como, do processo comunicacional do inteiro processo de planejamento territorial. Ou seja, em todas aquelas atividades endereçadas para o incremento da competitividade local.

Lotti (1998), por exemplo, sublinha que o desafio da competitividade não envolve somente o privado:

É possível intervir nas estruturas de uso coletivo, bancos, escritórios, escolas, hospitais e sobre a sua capacidade de ser acolhedor; setores cuja a sua projetação não foi até agora assumida por ninguém e na qual o designer poderá dar uma fundamental contribuição (LOTTI, 1998, p. 40, tradução nossa).

Uma abordagem de projeto similar pode ser também aquela apta para atuar no, assim dito, terceiro setor, isto é, naquele conjunto de instituições que ao interno do sistema econômico se colocam entre o Estado e o mercado, mas que não são reconhecíveis nem a um, nem ao outro. São sujeitos organizativos de natureza privada mas voltados para produção de bens e serviços com destino público ou coletivo como, por exemplo, as cooperativas sociais, as associações de promoção social, as associações de voluntariado, ONGs entre outras. Além disso, como observa Latouche (2005), a importância de fortificar a cooperação se traduz também na transmissão desta abordagem para outras esferas do cotidiano:

\footnotetext{
Na Europa, mas também nos Estados Unidos, no Canadá e na Austrália, se assiste a novos fenômenos: o nascimento daqueles que foram definidos novos-agricultores, novoscampesinos, novos-artesãos. Se observa o florir de uma miríade de associações sem fins lucrativos (ou, pelo menos, não exclusivamente com fins lucrativos): empresas cooperativas em autogestão, comunidades neo-rurais, LETS (Local Exchange Trading System) e SEL (Système d'Echange Local), bancos do tempo, comitês de bairro, creches familiares, associações de artesãos, agricultura camponesa, bancos éticos, movimentos para o comércio équo e solidário, associações de consumidores etc. [...] Realizar a sociedade local significa não se entrincheirar num terceiro setor, mas, colonizar progressivamente os outros dois, ou seja, o mercado capitalista e o Estado. Se trata também de se apoiar a uma democracia local revitalizada (LATOUCHE, 2005, p. 90-91, tradução nossa).
}

Adotando este modelo de interpretação encontramos, portanto, que a prática de uma abordagem de design orientada para o incremento da competitividade e da sustentabilidade local conduz a dois principais comportamentos profissionais: o primeiro é aquele de designerpropositivo, ou seja, de propositor de sistemas de produtos e serviços para uma determinada empresa, setor produtivo ou instituição, seja pública ou privada, que age em nível local (cooperativo ou associativo) e que tenha implicações com as comunidades ou associações de bairro; o segundo é 
aquele de designer-mediador, ou seja, de coordenador ou gestor de uma equipe, ou mais grupos de projeto, dentro de um programa mais amplo em nível territorial, com implicação dos setores produtivos, profissionais e das administrações públicas. Em ambos os casos, o designer recobre também o papel de responsável pelas ações de desenvolvimento de produtos e serviços ao interno de equipes multidisciplinares e de facilitador dos processos de projetação participativa e de codesign. Para Manzini (2009), uma tal transformação na figura do designer pode ser atribuída as constantes e velozes mudanças sobre as quais esta disciplina está hoje submetida:

\begin{abstract}
Nesses três decênios mudaram profundamente e velozmente tantas coisas. E, obviamente, mudou e está mudando profundamente e velozmente também o Design, a natureza dos seus produtos e o papel dos seus atores, entre os quais, o próprio designer [...] o objeto do design, aquilo que foi sempre referido com o termo "produto" transformou-se num sistemaproduto que ao mesmo tempo se estendeu e se complexificou. O resultado é um híbrido de elementos tangíveis e intangíveis; um conjunto de interações, físicas e sociais, que veiculam experiências; um sistema que compreende também o contexto no qual o produto do projeto vai se colocar [...] os designers, encontrando-se a trabalhar ao interno de grupos de projetação sempre mais amplos e variados, têm o seu papel progressivamente transformado para aquele de facilitador de processos, cuja a criatividade e cujas específicas competências (e as visões e propostas que disto derivam) vão estimular e orientar a criatividade e as capacidades projetuais dos outros atores do processo (MANZINI, 2009, p. 7, tradução nossa).
\end{abstract}

Nestas circunstâncias, o sistema-produto acima referido deve ser compreendido como o conjunto composto pelo produto, o serviço, a comunicação e mais todos aqueles elementos tangíveis e intangíveis que destes derivam. Para Manzini e Jégou (2003, p. 232, tradução nossa) este sistema compreende atividades muito diversas: "Daquelas relativas a definição da identidade de uma empresa, de uma linha de produtos ou serviços; a reconfiguração das atividades de uma empresa; até a pesquisa por convergências entre os diversos atores e operadores necessários para se obter um dado resultado".

Os serviços, são entendidos como prestações que produzem resultados. Tais resultados representam soluções complementares e alternativas aos artefatos. De acordo com Pacenti (2004), os serviços podem ser classificados inicialmente segundo o critério representado por sua finalidade de uso:

Existem serviços para fazer e serviços para saber. O fazer está associado a uma ação sobre o mundo. O saber, ao contrário, sobre as modificações do estado cognitivo da pessoa [...] É possível distinguir as performances entre aquelas que produzem uma modificação do estado físico diretamente sobre a pessoa, como por exemplo, um corte de cabelos, um tratamento médico ou um deslocamento físico; daquelas que não agem diretamente sobre a pessoa, mas sobre os produtos que constituem as suas próteses, como os serviços ligados a existência dos produtos, aos seus usos e manutenção; e aquelas ligadas à manutenção das condições socioambientais e aos espaços públicos nos quais as pessoas vivem, como os serviços de natureza infraestrutural, o fornecimento de energia, água, os serviços de segurança pública, ou aqueles de manutenção dos espaços públicos (PACENTI, 2004, p. 168, tradução nossa). 
A comunicação é considerada como o conjunto dos conteúdos e modelos informacionais e comunicativos relativos aos produtos, aos serviços, às estratégias e às programações necessárias para fazê-los operar. Para Pacenti (2004, p. 168, tradução nossa), a comunicação "cobre todos aqueles âmbitos cuja a ideação dos conteúdos descende, em grande parte, da sua comunicabilidade". Abrange, além disto, a análise, a compreensão e a gestão dos fluxos de informação, a definição dos instrumentos e dos objetos para dar voz a sociedade e a toda a documentação consequente das atividades projetuais.

\section{Em busca da inovação sustentável}

Dentro dos princípios da sustentabilidade os projetos que buscam inovar podem ser criados através da proposição de novos cenários correspondentes a estilos de vida sustentáveis. Segundo Vezzoli e Manzini (2007, p. 5, tradução nossa): "Significa desenvolver, no plano sociocultural, atividades inclinadas para a promoção de novos critérios de qualidade e, em perspectiva, modificar a própria estrutura da demanda por resultados".

A inovação pode ser também promovida através da proposição de novas interações entre os atores socioeconômicos. Para Vezzoli e Manzini (2007, p. 196, tradução nossa), "este tipo de inovação refere-se à oferta de produtos e serviços estruturados de acordo com o conceito de ecoeficiência de sistema, isto é, nas situações onde é interessante economicamente para as empresas uma redução, em nível sistêmico, do consumo dos recursos".

Segundo Manzini e Jégou (2003, p. 15, tradução nossa), “a responsabilidade dos projetistas não é somente aquela de conceber artefatos, mas é, também, aquela de facilitar o desenvolvimento e a condução das capacidades projetuais difusas inerentes a todas as pessoas e dos contextos e ambientes que favorecem a sua implementação".

Outros sim, Manzini (2008, p. 61-62) se refere as mudanças no modo como_os indivíduos e as comunidades agem para resolverem seus problemas e criarem novas oportunidades com o termo “inovação social”: "Tais inovações são guiadas mais por mudanças de comportamento do que por mudanças tecnológicas ou de mercado, geralmente, emergindo através de processos organizacionais baseados numa abordagem de baixo para cima [bottom-up]".

Inovações também podem ocorrer em relação aos significados. De acordo com Verganti (2009, tradução nossa), as inovações de significado são aquelas que "identificam o que as pessoas desejam, ou podem vir a desejar, e como elas receberão e perceberão as novas propostas". Este tipo de inovação exige a investigação e o entendimento de como ocorre a evolução na vida das pessoas em termos socioculturais e técnicos. Portanto, existe um contexto emocional, psicológico e 
sociocultural embutido neste processo, que depende dos valores, das crenças, das normas e das tradições.

Igualmente, inovações sustentáveis podem ser promovidas através do melhoramento na prestação dos serviços públicos. De acordo com o Design Council Research Team (2008, tradução nossa), o Design pode promover a inovação através da criação de valor público a partir de cinco princípios:

a) Desenvolvimento de serviços personalizados: as técnicas de projeto desempenham um papel fundamental na identificação das exigências dos usuários e na projetação dos serviços adequados entorno a eles. Por exemplo, através do uso de técnicas para mapear visualmente as trajetórias ent-to-end do usuário (Figura 1 e Figura 2) onde, em base nas experiências de um pequeno grupo destes, os operadores de um serviço podem assinalar uma série de potenciais solicitações que a observação de um cliente isoladamente não poderia evidenciar.

Figura 1 - Ferramenta Customer Journey Map, "The Trainride"

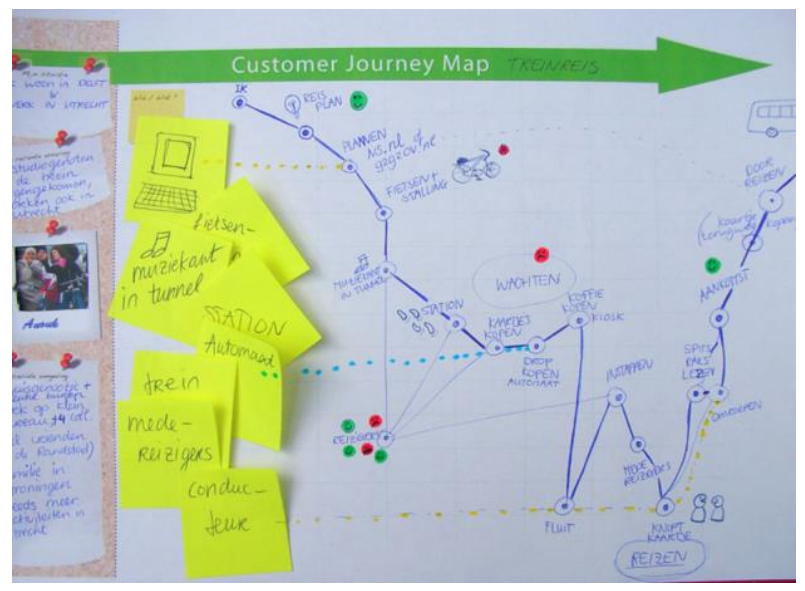

Fonte: Service Design Tools (TASSI, 2009)

Figura 2 - Ferramenta Role Play, "Go Project"

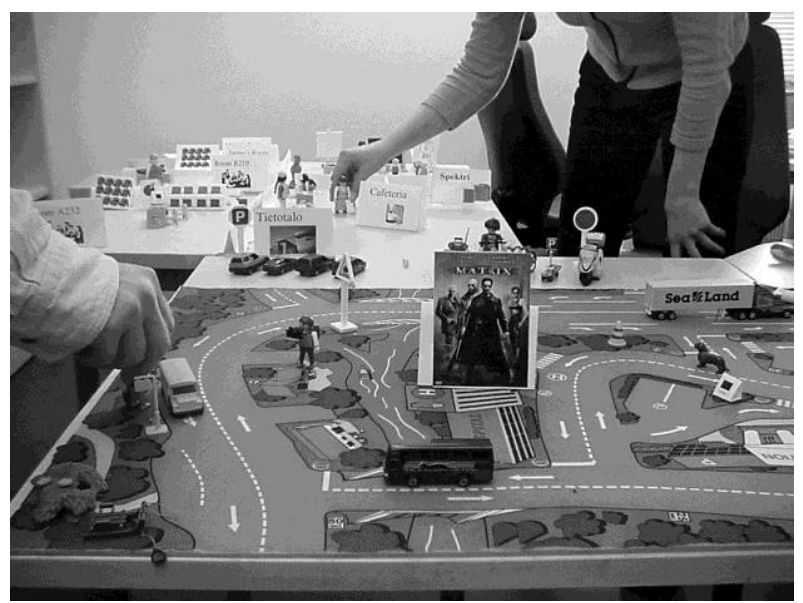

Fonte: IACUCCI, KUUTTI e RANTA (2009) 
b) Emprego dos conhecimentos do pessoal em primeira linha: as técnicas de projeto participativo e de co-design são capazes de fazer uso do conhecimento das pessoas em primeira linha no melhoramento dos serviços. Nas sessões participativas, os projetistas podem ajudar o pessoal a entender como poderia funcionar as suas ideias num contesto de projetação do serviço;

c) Gestão de risco das novas ideias: o uso de técnicas de projetação de protótipos (Figura 3) permite a gestão do risco através de uma acurada análise dos problemas já nas fases iniciais do projeto.

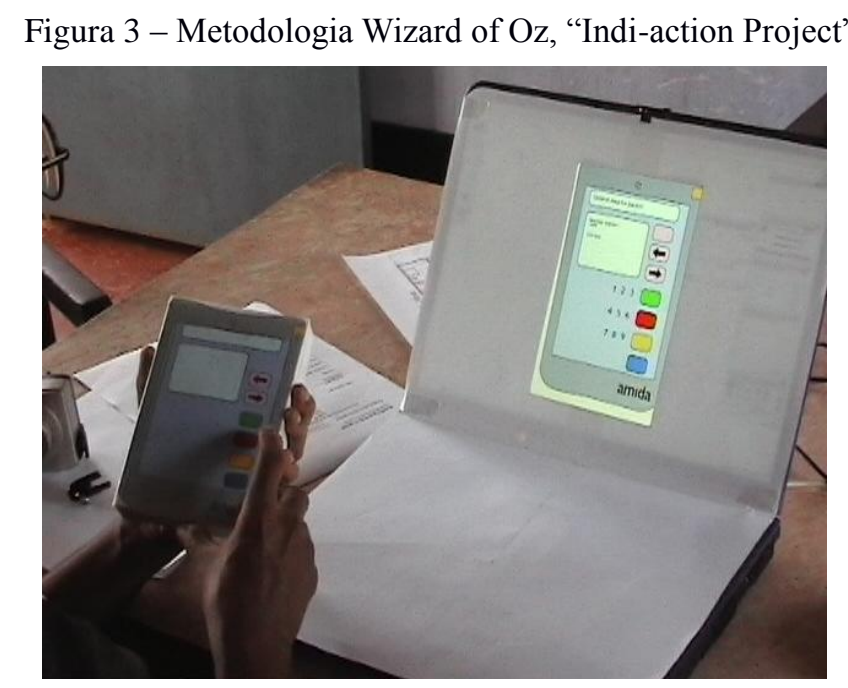

Fonte: KOOIJMANS et al. (2009)

d) Melhoramento da eficiência e da utilização dos recursos: a inovação pode ser favorecida através do uso de softwares de base de dados melhorando e otimizando a utilização dos recursos identificando as ineficiências (Figura 4).

Figura 4 - Base de dados, “Ask Nature”
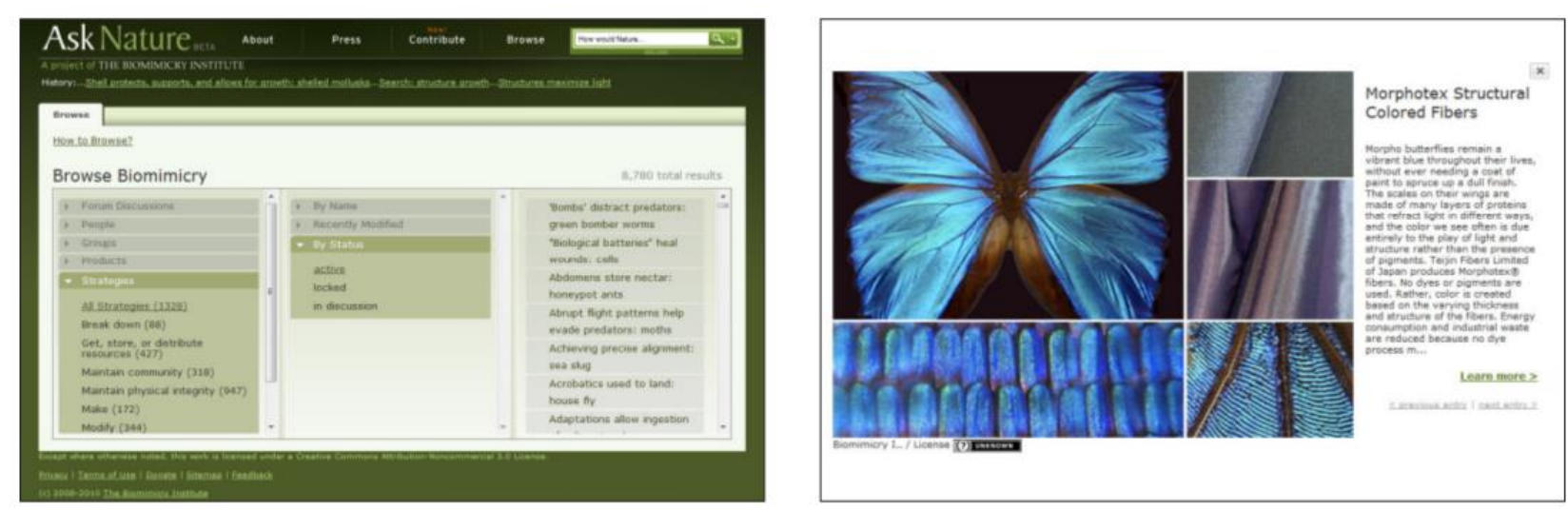

Fonte: BIOMIMICRY INSTITUTE (2008)

e) Atribuindo ao usuário mais controle: o princípio do Design Centrado no Usuário [Usercentered Design] pode promover o uso mais autônomo dos serviços. Por exemplo, na área da saúde, 
pode ajudar as pessoas a tomar o controle do próprio estado de saúde, encorajando-as a efetuar o autocontrole e a desenvolver os canais de comunicação mais eficazes entre os pacientes e os seus fornecedores de tratamentos médicos.

\section{O metaprojeto como plataforma para projetos sustentáveis}

Como um elemento determinante da fase de estruturação do problema, o metaprojeto se configura como o período de coleta das informações relacionadas aos objetivos que se pretende alcançar, aos meios que se pode dispor e às condições específicas do contexto em que se deve intervir. Segundo Deserti (2003):

Metaprojeto é o momento da definição dos vínculos do projeto, que nasce da consideração das exigências de uma pluralidade de sujeitos que devem ser considerados como referência para o próprio projeto, seja que resultem parte ativa ou que façam parte somente de forma ideal (DESERTI, 2003, p. 18, tradução nossa).

Collina (2005), entende o metaprojeto como:

O período que se coloca como gerador de múltiplas soluções para o inteiro processo ideativo: em fase propositiva, dando origem as hipóteses de projeto; em fase de desenvolvimento das soluções, trabalhando sobre aquilo que existe, transformando, modificando, hibridando, organizando como sistema as soluções já existentes; em fase de seleção da solução, aprofundando o contexto de referência relativo aos comitentes, aos usuários, aos aspectos normativos e produtivos; e, também, operando um processo de falsificação das hipóteses de projeto propostas [...] O metaprojeto pode declinar-se em diversos papéis: como atividade geradora de sucessivas operações de projeto, que em diferentes modos, coloca vínculos ou expressa as diretrizes para os projetos que descenderão; como produto de uma ação projetual finalizada para a coleta de informações (requisitos e prestações) daqueles vínculos, prescrições, indicações ou orientações; como informação complexa relativa aos objetivos perseguidos (definidos em base das expectativas dos usuários, dos destinos funcionais e das instâncias tecnológicas), aos meios à disposição e ao contexto de referência; enfim, como instrumento de verificação dos resultados no que diz respeito as funções institucionalmente a eles atribuídos [...] $\mathrm{O}$ metaprojeto pode assumir, além disso, o papel de plataforma de comunicação, compartilhando as informações entre atores provenientes de diferentes disciplinas do projeto, mas não só, também entre diferentes figuras empreendedoras, até compreender os próprios destinatários do projeto (COLLINA, 2005, p. 22-39, tradução nossa).

Focalizando o trabalho sobre cenários muito amplos, o metaprojeto não se concentra em um único artefato, mas reflete sobre o sistema. Ainda segundo Collina (2005):

É um modo projetual que leva à ideação não mais de artefatos, mas de visões, estratégias e cenários estendidos; de inteiros sistemas e famílias de produtos, planos estéticos globais capazes de coordenar linhas de diferentes produtos, programas de estilos formais que orientam os designers no desenvolvimento das sucessivas séries e variantes do produto; a elaboração não mais de propostas operacionais, mas sim, geratrizes capazes de ativar percursos e matrizes de inovação que se abrem para um leque de possíveis trajetórias projetuais (COLLINA, 2005, p. 68-69, tradução nossa).

Neste sentido, o projeto entendido como sequência de decisões depende das informações sobre as quais se baseiam tais decisões. Assim, a informação é entendida como conhecimento útil 
para as tomadas de decisão. Tomar uma decisão representa a seleção de uma entre diferentes alternativas. Para garantir que essas decisões tenham uma base sólida é necessário coletar muitos dados. O metaprojeto também se coloca como fase de coleta dos dados. Entretanto, propondo-se como uma etapa projetual encarregada de recolher não só informações quantitativas, mas, de todas as informações úteis e relevantes que ajudem o processo decisório e o decorrer das suas ações.

\section{Considerações finais}

Numa abordagem metodológica que seja capaz de orientar o projetista na pesquisa de soluções sustentáveis, as fases analíticas do problema deverão ser estendidas em relação as tradicionais estruturas de projeto. Além disso, a intensa conexão dos problemas com o território requer ferramentas de investigação adequadas para a exploração contextual. O metaprojeto, como fase pré-projetual, aparece portanto como o momento apropriado para efetuar tais investigações.

Então, o metaprojeto coloca-se como o período no qual ocorre a percepção e a análise dos problemas [problem finding] e a investigação contextual [problem setting] referentes ao momento da estruturação do problema de projeto. A análise dos problemas é o momento no qual o projetista, através da sua experiência e conhecimento do contexto, pode relacionar os problemas e as necessidades observadas com as possíveis categorias de solução. Isto pode ser feito através da elaboração de um mapa que contenha as relações entre as necessidades e os atributos de qualidade adequados para atendê-las. Nestas relações, emergem os modelos materiais (produtos, utensílios, dispositivos, estruturas, sistemas entre outros) e imateriais (serviços, comportamentos, atitudes, estratégias, entre outros) que podem ser ativados através de um proposital planejamento que preencherá as séries de necessidades identificadas.

Logo, o metaprojeto pode constituir o momento destinado para a formulação de uma diagnose do contexto. Uma vez que, nos projetos focados na localização, a necessidade de ter um feedback que assegure as escolhas e garanta um certo grau de segurança sobre o resultado final é um fator indispensável, a participação dos atores (usuários, fruidores, operadores e decisores), ou de suas representações, deve ser um processo que acompanha a evolução de todo o processo projetual. O envolvimento dos decisores (públicos e privados), por exemplo, tem tanto uma finalidade de sensibilização quanto de uma participação ativa no processo projetual, começando pela própria definição das propostas de intervenção. O projetista poderá assumir o papel de coordenador não somente das fases tipicamente de projeto e controle da execução do projeto, mas de todas as etapas, compreendendo, inclusive, aquelas precedentes ao design brief e posteriores a realização dos produtos e serviços. 
A interpretação destes princípios permitiu estudar as conexões necessárias para propor a estruturação de uma abordagem metodológica coerente com a ótica do design que considera as dimensões econômica, ambiental e social da sustentabilidade. Esta interpretação levanta uma principal consideração: a sustentabilidade e a competitividade das atividades produtivas locais, na complexidade dos problemas e na variedade dos contextos brasileiros, pode ser estimulada através de projetos endereçados para a valorização das características e das competências locais e orientados para a localização e o fortalecimento econômico das comunidades.

\begin{abstract}
Based on a bibliographic review, this text intends to discuss relations between the projectual method and the development of products and services, and it provides subsidies to the structuring of a methodological approach consistent with the perspective of a sustainable design. One of the assumptions is that, in sustainable design, social and environmental variables particular to a territory become the reference system and gain strength to address interpretation of subproblems and subsequent design decisions. From the connections found, it becomes clear the need of adopting a flexible approach capable of being modified, implemented or updated periodically according to the subject and the context of each project. This type of approach should be able to guide the designer in the search for sustainable solutions; therefore, the analytical phases of understanding the issues should be extended as compared to the traditional steps of the design. Likewise, we realized that the project's object was transformed into a system which at the same time expanded and become complex. The result is a system that also includes the context in which the project's product will be inserted. This intense connection among issues relative to the territory requires the use of research tools suitable for a contextual evaluation. Thus, the metaproject is presented as a time necessary for correct perception and analysis of the identified problems. More than finding definitive answers, the objective of this essay is to provide an effective contribution to the area of research and to development of products and services in an effort to support sustainability-driven system-oriented designs.
\end{abstract}

Key-words: method; product and service design; sustainable innovation.

\title{
Referências
}

BADALUCCO, L.; CHIAPPONI, M. Energia e design. Innovazioni di prodotto per la sostenibilità energetica. Roma: Carocci, 2009.

BIOMIMICRY INSTITUTE. Ask Nature. Biomimicry Institute, 2008. Disponível em: <http://www.asknature.org/>. Acesso em: 6 mar. 2015.

BONSIEPE, G. Teoria e pratica del disegno industriale. Elementi per una manualistica critica. Tradução de Marisa Bertoldini. Milão: Feltrinelli, 1975.

Diseño industrial, tecnología e dependencia. Mexico, D.F.: Edicol, 1978.

COLLINA, L. Design e metaprogetto. Teorie, strumenti, pratiche. Milão: Poli.Design, 2003.

DESERTI, A. Metaprogetto. Riflessioni teoriche ed esperienze didattiche. Milão: Poli.Design, 2003. 
DESIGN COUNCIL RESEARCH TEAM. The role of design in public services. Design Council Briefing, 2008.

Disponível em:

<http://www.sustainable-design-uk.com/pdf/DesignCouncilBriefing02_TheRoleOfDesignInPublicServices.pdf >. Acesso em: 6 mar. 2015.

IACUCCI, G.; KUUTTI, K.; RANTA, M. Go Project. In: TASSI, R. Role Play. Service Design Tools, 2009. Disponível em: <http://www.servicedesigntools.org/tools/42>. Acesso em: 6 mar. 2015.

KOOIJMANS, T. et al. IndiAction: a case study on user centered product design methods in rural India. Department of Industrial Design of the University of Technology Eindhoven, 2009. Disponível em:

<http://www.studiosophisti.nl/publications/SIDER05_IndiAction.pdf>. Acesso em: 6 mar. 2015.

LATOUCHE, S. Come sopravvivere allo sviluppo. Dalla decolonizzazione dell'immaginario economico alla costruzione di una società alternativa. Tradução de Fabrizio Grillenzoni. Turim: Bollati Boringhieri, 2005.

LOTTI, G. Il progetto possibile. Verso una nuova etica del design. Monfalcone, Go: Edicom, 1998.

MANZINI, E. Designer, utenti e co-designer. In: RIZZO, F. Strategie di co-design. Teorie, metodi e strumenti per progettare con gli utenti. Milão: FrancoAngeli, 2009. p. 7-10

MANZINI, E.; JÉGOU, F. Quotidiano sostenibile. Scenari di vita urbana. Milão: Edizioni Ambiente, 2003.

PACENTI, E. Design dei servizi. In: BERTOLA, P.; MANZINI, E. (Org.). Design Multiverso. Appunti di fenomenologia del design. Milão: Poli.Design, 2004. p. 164-176

TASSI, R. Customer Journey Map. Service Design Tools, 2009. Disponível em:

<http://www.servicedesigntools.org/tools/8>. Acesso em: 6 mar. 2015.

VEZZOLI, C.; MANZINI, E. Design per la sostenibilità ambientale. Bolonha: Zanichelli, 2007.

WATANABE, M. S. Induction Design. Un metodo per una progettazione evolutiva. Turim: Testo \& Immagine, 2004.

\section{Dados do autor}

\section{Nome: André de Souza Lucca}

Filiação institucional: Docente da Universidade Federal do Maranhão - UFMA

Endereço para correspondência: Cidade Universitária, Av. dos Portugueses, 1966, Bacanga - CEP 65080-805 - São Luís, MA - Complexo Pedagógico Paulo Freire, Asa sul, Sala 306

Telefone: (98) 32729166

e-mail: aslucca@yahoo.com.br

Submetido em: 07/03/2015

Aceito em: 14/09/2015 